\title{
Editorial
}

\section{Where is public communication of science going?}

We have published this issue of JCOM while the call for papers is open for the twelfth Public Communication of Science and Technology conference. The biennial meeting will be held in April 2012 and for the first time in Italy: the hosting city in Florence. ${ }^{1}$ The 2012 edition of the PCST conference is being held after more than twenty years of growth of the network of scholars that founded it and the expansion of its boundaries outside the European context from which it was created. JCOM is a part of this network, made up not only of individuals but also of organisations, university departments, journals, national conferences and so on. In previous issues of this journal we have tackled the question of the establishment of science communication as an academic field, and several prominent actors have highlighted the accomplishments science communication has reached during the last twenty years. ${ }^{2}$ The PCST conference, thus, is the occasion to further analyse the state of our community, as it will focus on subjects such as quality in science communication and the state of academic publishing in this field. With this brief, and I must admit, a bit provocative editorial, I would like to highlight the need to keep on debating the position and the future developments of science communication.

The PCST community is a common space that holds together not only scholars who work on the intersection between science studies and communication, but also scientists interested in communication dynamics, science journalists, museum curators, media companies and so on. The question I want to pose here is how much this community is able to influence the ecosystems in which it lives. I think that the main problem we are facing is that our community has not generated a fertile and productive ground around it, at least if we refer to its academic position. Its population is surely a lively one, but it is also static in the sense that its capacity to attract new people is low. The PCST community is hardly a reference point within the academy. I mean that while we have witnessed the emergence of departments, journals and conferences devoted to science communication, the ideas developed within this system have not crossed its boundaries to fertilise other grounds; therefore, our foundational disciplines such as social studies of science and communication studies have a bigger impact on the academy. Meanwhile, science communication often produces interesting things for its small community but seldom reaches a broader public. Furthermore, social studies of science and media studies have produced ideas that have had the ability to describe the social world beyond their disciplinary boundaries. The relationship with these elder siblings is not an easy one, as science communication hardly ever influences social studies of science and media studies scholars. On the contrary, science communication is an importer rather than an exporter of ideas.

Originality is one of the problems. While a small group of people maintain a high level of quality, having mastered a strong ability to identify key problems and interesting solutions, some areas of our community lack the capacity to produce recognizable and high quality results. Often, research merely applies well-established methods to science communication problems, resulting in knowledge that is new only within the boundaries of PCST. Perhaps this is a problem of maturity in the field as a whole and we need to work longer and harder in order to build a stronger, more original and cohesive community. But another problem is that the PCST community focuses on a rather small subject, and this challenges the very idea of considering public communication of science to be a discipline rather than a field of inquiry.

On the other hand, a discipline such as social studies of science suffers from a different type of problem: its high level of esotericism; the language itself makes it very hard to understand and translate outside the borders of the academy, limiting its ability to influence actors such as scientists and politicians. Instead one of the main drivers of the PCST field has been the production of a more coherent framework in which professionals, policy makers and people interested in the link between science and communication have found a way to improve their work. Indeed, the issues science communication focuses on are of primary importance in our societies. This enlightens what is perhaps one of the main issues at stake for the PCST community: to open up possible channels of communication with people who work outside universities. This is already happening, of course, and probably the suggestion made by Toss Gascoigne and his colleagues is one that could further push PCST in that direction: "not being a 
discipline may be more helpful, because it allows science communicators to plunder all disciplines and fields of study to conduct their work most effectively" ${ }^{3}$ Not being a discipline allows PCST to think not only in academic terms but also opens us up to outside creativity.

Alessandro Delfanti

\section{Notes and references}

${ }^{1}$ http://www.pcst2012.org/index.php.

2 See the collection of comments published by JCOM last year: N. Pitrelli (2010), Road maps for the 21st-century research in Science Communication, Jcom 09(03): C01.

${ }^{3}$ T. Gascoigne, D. Cheng, M. Claessens, J. Metcalfe, B. Schiele and S. Shi (2010), Is science communication its own field?, Jcom 09(03): C04, p. 5

How TO CITE: $\quad$ A. Delfanti, Where is public communication of science going?, Jcom 10(02) (2011) E. 